Voix et Images

voixetimages

\title{
Ça fait longtemps que c'est comme ça
}

\section{Jonathan Livernois}

Volume 41, numéro 1 (121), automne 2015

URI : https://id.erudit.org/iderudit/1033965ar

DOI : https://doi.org/10.7202/1033965ar

Aller au sommaire du numéro

Éditeur(s)

Université du Québec à Montréal

ISSN

0318-9201 (imprimé)

1705-933X (numérique)

Découvrir la revue

Citer ce compte rendu

Livernois, J. (2015). Compte rendu de [Ça fait longtemps que c'est comme ça].

Voix et Images, 41(1), 153-158. https://doi.org/10.7202/1033965ar d'utilisation que vous pouvez consulter en ligne.

https://apropos.erudit.org/fr/usagers/politique-dutilisation/ 


\section{E S S A I S / ÉT U D E S}

Ça fait longtemps que c'est comme ça

$+++$

JONATHAN LIVERNOIS

Université Laval

Voilà la parution simultanée de deux ouvrages que nous n'aurions pas pensé, évidemment, associer. François Ricard, cheville-ouvrière de la collection «Papiers collés» aux Éditions du Boréal, a eu une excellente idée. Lire d'un seul trait un choix de chroniques et de textes anciens d'André Langevin, décédé il y a six ans, et les essais de Jean Larose, qui n'avait pas publié de recueil depuis 1994, c'est faire un "pas de côté», pour le dire comme Ricard lui-même. Langevin et Larose ont en commun d'être de sévères juges de la Révolution tranquille. Le premier a vite quitté la fête de juin 1960. Le second y a-t-il seulement été convié?

Pendant les années 1980, Jean Larose était considéré comme un essayiste québécois de premier plan. En 1986, dans le magazine L'actualité, Georges-Hébert Germain lui consacrait même un portrait. On y voyait une photo de Larose en jeune intellectuel, veste de cuir, dans un décor aux allures postindustrielles. On le retrouvait aussi à la télévision, clouant solidement le bec de la bande des six, en direct du défunt Lux et sur les ondes de la défunte Radio-Canada. Il me semble qu'il y avait, sur ce plateau, un futur académicien, mais je peux me tromper. De manière moins anecdotique, on se souviendra également de son débat avec Jacques Pelletier, en 1994, tandis que ce dernier le considérait comme un des tenants (avec Ricard, Jacques Godbout et Denise Bombardier) de la «droite culturelle» au Québec. Après avoir publié deux romans au succès mitigé et avoir écrit quelques chroniques dans Le Devoir, il revient s'installer, vingt et un ans après son dernier recueil, La souveraineté rampante (1994), dans son milieu naturel : l'essai. En verve, il publiera même, cet automne, de Nouveaux essais de littérature appliquée, dont le titre associera plus ou moins adroitement le moteur de recherche et la dissidence soviétique: Google goulag.

Entre 1994 et aujourd'hui, sur le plan politique, il y a bien eu un référendum, le passage de Lucien Bouchard du statut de sauveur à celui de lucide, l'élection de Jean Charest, le printemps 2012 (dont Larose ne parle pas), la victoire de trois semaines du Parti québécois ainsi que le retour à la normale avec un gouvernement libéral qui gouverne la province comme un centre commercial de troisième ordre. Il y a eu quelques romans, deux ou trois recueils de poésie et cette impression permanente, chez plusieurs dont Larose, qu'il y a une crise et un lent effritement de la culture québécoise. Le décor est planté: 
À distance, chacun des essais ici réunis me semble un effort pour faire brèche dans la folie, l'amnésie, la soumission, le nihilisme - avec Kafka, Pessoa, Arendt, tant d'autres que j'admire, Chalamov, Rimbaud, Proust, Montaigne, Miron, dont l'amitié me soutient, tout un réseau où je n'ai pas la prétention de pouvoir m'inscrire, mais le désir d'essayer, si une aile ne m’y pousserait pas ${ }^{1}$.

Depuis longtemps, Jean Larose traîne un bagage d'élitisme et de mépris pour un Québec jamais à sa hauteur. Plusieurs textes de L'amour du pauvre (1991) font mal à ce sentiment qu' on cachera, presque honteux: le patriotisme. En 1986, quelque temps après qu'il a eu tiré à boulets rouges sur La Barre du jour et La Nouvelle Barre du jour ainsi que sur un dossier de Voix et Images leur étant consacré, on le représente dans cette dernière revue à la manière d'un chevalier avec ses armes et son heaume. Je crois qu'on voulait insister sur l'idée que son combat en était un d'arrière-garde... Si Larose a déclenché et déclenche encore moult émotions négatives que je peux fort bien comprendre, je suis toujours resté un peu mixed feelings, comme on dit à Ogunquit, face à son travail d'intellectuel et d'essayiste. Les raisons sont purement et simplement personnelles: c'est dans son cours sur l'œuvre de Proust, à l'Université de Montréal, que j'ai compris que ce que je cherchais en histoire ou en philosophie, je le trouverais en littérature. Entre l'identification de cités-États sur une carte de la Grèce ancienne et la lecture de Gilles Deleuze et de Georges Bataille, j'ai rapidement fait mon choix. Je ne caricature même pas.

Tout ça pour dire que j'ai lu le recueil de Larose avant de lire celui d'André Langevin. Est-ce que le propos serait celui d'un contempteur à tout crin du Québec d'aujourd'hui? S'indignerait-il encore que la chaîne culturelle de Radio-Canada soit devenue une chaîne musicale où même une chatte, si elle était mélomane, perdrait son chaton? Dans Essais de littérature appliquée, ce n'est pas nécessairement ce qu'on percevra.

D'entrée de jeu, la littérature est sortie des serres chaudes qu'elle a pu connaître, en d'autres lieux:

\begin{abstract}
En un temps où la société est plus cyniquement inégalitaire qu'elle ne l'a été depuis un siècle, où les médias encensent le sport d'élite, les entrepreneurs d'élite, les cigares, les Van Gogh et les jets privés de l'élite de l'argent, ce n'est pas pour les dominants une petite réussite en décervelage idéologique que d'être parvenus à imposer l'idée que la littérature, avec toute la culture à mémoire longue, est élitiste et réactionnaire. (16)
\end{abstract}

Les écrivains, dans ce contexte, qui ont le statut enviable de paria et de quêteux (insérer ici les commentaires tonifiants de la droite sur les artistes), ont cette pauvreté qui permet la vérité du dénuement. L'écrivain dont tout le monde se fout est fatalement exclu des grands projets d'ici, ceux qui impressionnent, qu'il s'agisse d'un cimetière pour chiens sur une île de la région métropolitaine ou du retour d'équipes sportives disparues. Ainsi vont nos ambitions communes. L'écrivain, qui n'est plus

1 Jean Larose, Essais de littérature appliquée, Montréal, Boréal, coll. «Papiers collés», 2015, p. 22. 
conscrit, est libre d'aller où il veut. Il peut tendre vers l'authenticité, comme le mauvais pauvre garnélien, ébréché au possible. Il n'arrivera pas au bout. On connaît la suite du texte de Garneau: un «etc.» à la manière d'une vis sans fin. Larose est encore, près de vingt-cinq ans après L'amour du pauvre, un lecteur pénétrant de Saint-Denys Garneau.

Étant donné que Larose n'a pas publié de recueil d'essais depuis 1994, ses textes, qui vont de la brillante analyse du film que Martin Scorsese consacre à Bob Dylan (No Direction Home, 2005) au mémoire de l'UNEQ présenté aux États généraux sur l'état du français, se sont accumulés dans le tiroir. Avec quelques décalages. Reprendre un essai consacré au "cinéma de 1995", encenser Eldorado de Charles Binamé et descendre en flammes Le confessionnal de Robert Lepage, ça semble aussi pertinent que de faire du patin à roues alignées. Aussi, il rappelle, dans un texte de 1999, qu'il peut désormais, grâce à la technologie, faire plusieurs choses simultanément, comme écouter le Téléjournal en ligne et répondre à une personne «qui veut chatter sur ICQ». Voilà un acronyme qu'on avait presque oublié. À cause de la distance temporelle, lorsque Larose écrit que le «multimédia, c'est la technique devenue arrogante et sûre d'elle, comme le manifeste du surréalisme» (59), il donne l'impression d'être encore prisonnier d'un univers qui ne le contraint déjà plus. En témoigne son projet de radio culturelle sur le Web, Globe sonore, lancé en 2011. Cela dit, c'est sans doute le texte le plus ancien - 1994 - du recueil qui retiendra l'attention du lecteur: «Naissance d'un essayiste: Marcotte aux commencements ». Cette préface à la réédition d'Une écriture qui se fait (1962) de Gilles Marcotte permet de prolonger la réflexion sur le caractère peut-être non romanesque de la littérature québécoise et sur la difficulté d'être de son roman, bien mis en perspective par les travaux récents de Michel Biron et d'Isabelle Daunais.

Il y a une parenté entre Essais de littérature appliquée et le recueil d'André Langevin, et ce, dès le texte liminaire du recueil de Larose, qui s'ouvre sur une rencontre fortuite entre René Lévesque et lui, en 1972, au petit matin, dans le parc La Fontaine. Nostalgie de l'essayiste pour une voix, éraillée puis forte, qui n'est plus celle des indépendantistes d'aujourd'hui, dont les formules creuses lors de la défaite d'avril 2014 ont paradoxalement mis en relief la qualité de la langue du nouveau premier ministre. Cela participe du grand problème qui est déjà celui qu'identifiait André Langevin:

Français de désir, français de culture, français de mémoire, c'est le même, et c'est aussi le français de la liberté. Le projet national fut porté par l'amour de la langue transmis jusqu'à nous pendant deux siècles de résistance à l'anglais, mais c'est le souverainisme progressiste du Parti québécois qui a rétabli notre francophonie dans son héritage des Lumières. La Révolution tranquille est la courte époque où des intellectuels ont œuvré comme accoucheurs de liberté. [...] Le Parti québécois n'a pas compris que le succès du mouvement qu'il incarnait dépendait de sa fidélité à la tradition qui liait, dans le mouvement vers l'indépendance nationale, une langue de culture et l'humanisme moderne. (12) 
Ce débat-là n'était-il pourtant pas réglé? Cet appel au français de désir et de mémoire est-il une preuve que le chevalier Larose a repris son combat d'arrièregarde? Rappelons plutôt, en guise de réponse à cette question, les mots qu'il associait aux remises en question de Gilles Marcotte au tout début de la Révolution tranquille: "L'écrivain québécois a enterré depuis belle lurette son prédécesseur canadien-français! Enterré, oui, sans doute, répondrait Marcotte, mais l'a-t-il bien tué et mangé avant? Le Québécois est-il parvenu à créer sain?» (38) Larose n'a eu de cesse de le rappeler dans ses essais depuis Le mythe de Nelligan (1981): les Québécois vivent bien avec l'impression que les problèmes sont déjà toujours réglés. Sans effort, grâce à la Révolution tranquille devenue une formule incantatoire, les Québécois seront devenus laïques et souverains; ils auront obtenu une reconnaissance pleine et entière de leur langue, grâce aux bons soins du Docteur Laurin. Entre-temps, dans ce monde qu'on qualifierait naïvement de réel, le souverainisme est passé à la gestion à la petite semaine, délaissant l'idée même que ce mouvement devrait susciter des émotions et des emballements qu'un contribuable ne ressent pas en temps normal. S'il veut des émotions, qu'il les cherche ailleurs. Autrement dit, le souverainisme, sûr de son affaire, s'est détaché de la langue, vecteur de rêves et de projets, pour la réduire à un moyen de communication. La loi 101 est une bonne police d'assurance et a déjà réglé tous nos problèmes, sur ce plan. À lire le recueil d'André Langevin, Cet étranger parmi nous², on comprend que l'illusion a de belles racines dans cette Révolution tranquille que ce dernier regardait, déjà, l'œil méfiant.

Karim Larose a fait ici un excellent travail en colligeant et en présentant ces textes d'André Langevin, qu'on a réduit trop souvent à Poussière sur la ville. On reste pantois devant la date de parution originale du premier texte: 1945. L'homme a à peine dix-huit ans et déjà, on le sent propulsé dans des enjeux d'après-guerre qui définiront durablement le Québec: réflexions sur la responsabilité des écrivains (il assiste aux conférences de Sartre à Montréal), attention particulière à la naissance du théâtre d'ici, prise de parole au cœur des débats sur l'apport de la littérature française à celle du Canada français, qui culmineront dans La France et nous de Robert Charbonneau - dont il fait un portrait pour Notre temps, en 1947. D'ailleurs, on peut lire dans ce dernier texte ces deux mots qui auront un grand impact dans quelques années: "colonialisme littéraire». Ces mots reviennent dans un texte paru dans Le Devoir en 1956, et qui marque une sorte de saut qualitatif tant sur le plan formel que sur celui des idées: «Nos écrivains dans leur milieu». Langevin y écrit:

Le Canadien français découvre avec stupeur qu'il est solidaire de tous les autres hommes, que la planète tend à craquer, qu'il appartiendra, bon gré mal gré, à l'une des deux moitiés, avec des Noirs, des Jaunes, des Esquimaux ou des Lapons. En

2 André Langevin, Cet étranger parmi nous. Essais et chroniques, textes choisis et présentés par Karim Larose, Montréal, Boréal, coll. «Papiers collés», 2015, p. 90. 
d'autres mots, le sort de l'espèce tend à minimiser un peu celui du "groupe ethnique» et l'intellectuel canadien-français se cherche sur les deux plans. Cette lucidité dont il se trouve tout à coup affligé, parce qu'une fenêtre a été ouverte sur un monde en instance de fission et parce que 60000 paysans ont mis trois cents ans à engendrer des intellectuels, lui donne le vertige.

Ce vertige, Langevin le vivra lui-même, «étranger» parmi les siens, comme le rappelle pertinemment Karim Larose.

L'étranger parmi les siens, c'est aussi celui qui joue le rôle de l'éteignoir. Ses textes des années 1960, surtout parus dans l'éphémère Nouveau Journal et au Maclean, rappellent çà et là les chroniques d'André Laurendeau, à la même époque, réunis dans Ces choses qui nous arrivent (1970), que personne ne semble avoir eu jusqu'ici l'idée de rééditer. On y découvre l'affirmation répétée que juin 1960 n'est pas le terminus de l'histoire québécoise et qu'il serait dangereux de se reposer, assis sur des lauriers en plastique. Par exemple, comparant Jean Lesage à Créon, André Langevin écrit:

La révolution tranquille n’a jamais eu lieu que dans les discours de Créon. Avec lui, une nouvelle élite, une nouvelle droite a pris le pouvoir. Rien de plus. [...] Les fondements de l'ordre établi, qu'on suspectait si fort naguère, sont de nouveau inviolables. C'est que le régime n'a pas mis de temps à s'identifier à l'ordre établi. L'heure est venue de faire prendre un peu d'air à la statue de Duplessis... (199)

Ce sera chose faite en 1977.

L'éducation, la laïcité et la langue française sont au cœur des préoccupations de Langevin. En 1969, il propose même une sorte de nationalisation des universités québécoises, au sein de la nouvelle UQAM. Le Rapport Parent, qui offrait tout de même "l'indispensable instrument d'une véritable libération», n’a pas tout réglé, loin de là. Paul Lacoste l'écrira en 1964, et ces mots auraient pu être ceux de Langevin: «Ce qui est le plus grave pour l'avenir de la Province, ce n'est pas que le rapport Parent ait été en bonne partie écarté, c'est que le public puisse croire que l'essentiel du rapport a été adopté et que nous avons enfin un système moderne et démocratique ${ }^{3}$.»

La langue française et l'État unilingue: c'est ce que propose, en 1961, André Langevin, convaincu que la véritable indépendance passera par la langue française. L'année suivante, il le dit sans ambages:

Tout indique que nous ne pourrons insuffler une vie nouvelle à notre culture que dans un État de langue française, où le pouvoir politique sera un pôle d'attraction plus puissant que le pouvoir économique. Notre originalité française ne sera plus alors une vague relique folklorique, mais une réalité inscrite dans les faits de tous les jours, que le capital anglo-saxon devra respecter, comme il est obligé, en Amérique du Sud, par exemple, d'accepter la culture latine. (166)

3 Paul Lacoste, cité par Yvan Lamonde, L'heure de vérité. La laïité québécoise à l'épreuve de l'histoire, Montréal, Del Busso, 2010, p. 115. 
Ce respect de la réalité et de la culture sud-américaines par les États-Uniens, Salvatore Allende, quelques années plus tard, en sera un peu moins convaincu, mais bon... Langevin lâche le mot: "Sur le plan culturel, il est indéniable que seule la souveraineté du Québec peut arrêter une déperdition de force qui, autrement, sera fatale, à plus ou moins brève échéance.» (166) On le sait: il n'y aura pas de souveraineté mais une loi identifiée par le numéro 101, fût-elle charcutée avec le temps et rafistolée avec des outils dérisoires - en témoignent les dernières modifications par règlement proposées, en juin 2015, par le gouvernement Couillard.

Nous sommes sauvés et nous le savons de moins en moins. C'est sans doute la raison pour laquelle Jean Larose a réuni ces essais, et que son texte liminaire reprend là où Langevin avait laissé le Québec, cinquante ans plus tôt. C'est le sens à donner à cette littérature appliquée. 